\title{
FABRICATION OF THICK ANODIC FILMS ON 304-TYPE STAINLESS STEEL FOR BINDER- FREE SUPERCAPACITORS
}

\author{
${ }^{1}$ Yingge WANG, ${ }^{2}$ Gang LI, ${ }^{1}$ Kaiying WANG, ${ }^{1}$ Xuyuan CHEN \\ ${ }^{1}$ Department of Microsystems-IMS, University of South-Eastern Norway, Horten, Norway, \\ Yingge.wang@usn.no \\ ${ }^{2}$ Center of Nano Energy and Devices, College of Information and Computer \& Institute of Energy Innovation, \\ Taiyuan University of Technology, Taiyuan, China, \\ ligang4122001@gmail.com
}

https://doi.org/10.37904/nanocon.2019.8478

\begin{abstract}
We report the fabrication of thick nanoporous oxide films on stainless steel (SS) foils via long-term constantpotential anodization at room temperature. The anodization potential of $50 \mathrm{~V}$ was employed for 1,2 and $3 \mathrm{~h}$, respectively to form the anodic films with different thickness. The effects of anodic film thickness on supercapacitance behavior have been further investigated as binder-free electrodes. It is found that the anodic film thickness increases linearly with the anodization time while the electrochemical behaviors of anodic film were not proportionally enhanced with the thickness. Furthermore, the formed anodic layers formed at $50 \mathrm{~V} / 3$ $\mathrm{h}$ exhibits the highest area capacitance $\sim 215 \mathrm{mF} \mathrm{cm}^{-2}$ at $1 \mathrm{~mA} \mathrm{~cm}^{-2}$, and the capacitance still retained $58.9 \%$ of its initial value after 1000 cycles.
\end{abstract}

Keywords: Nanoporous anodic film, stainless steel, supercapacitance, thickness

\section{INTRODUCTION}

Supercapacitors are promising as fast electrochemical energy storage devices with acceptable energy density and fast charging rate, which exhibit extremely higher power densities and longer cyclic life as compared to batteries such as Li-ion and alkaline batteries and higher energy densities when compared to conventional electrostatic capacitors [1,2]. Basically, supercapacitors are divided into (a) carbon-based electric double layer capacitors (EDLCs) and (b) redox-based pseudo-capacitors on the basis of different electrochemical charge storage mechanisms. In the former case, EDLCs depend on the charge adsorption/desorption at the electrode/electrolyte as a result of the electrostatic attraction. In the latter case, pseudo-capacitors rely on the redox reactions (Faradaic reactions) at the surface and near-surface of electrode materials between electrode and electrolytes [3,4]. Compared to typical EDLCs, pseudocapacitors show substantially higher specific capacitance and energy density that are more favorable for practical application.

Nevertheless, the practical application of pseudocapacitors is still hindered due to their limited electrochemical properties caused by poor electrical conductivity and low specific surface area [5-8]. Recently, various types of nanoporous and nanotubular anodic oxide films attracted attention as potential porous electrode materials due to their unique porous structure, high surface area, facile fabrication processes, and free of current collectors. Among these films, highly porous oxide films formed on stainless steel is more promising candidate to act as nanoporous active materials, because they can provide high pseudo capacitance due to more reaction sites of large surface area nanostructured $\mathrm{Fe}_{2} \mathrm{O}_{3}$, and acceptable electrical conductivity of $\mathrm{Fe}_{3} \mathrm{O}_{4}$. However, the limited thickness of the anodic films on stainless steel substrates via galvanostatic anodization is generally restricting the mass of active materials [9-13]. Furthermore, the effects of film thickness on supercapacitance behavior of anodic oxide films have not been well studied because it is difficult for electrolyte ions to penetrate into thick nanoporous films. Therefore, to fabricate thick anodic film on stainless steel and 
further investigate the effects of film thickness on supercapacitance behavior of anodic oxide films are significant for developing high-performance supercapacitors.

In this work, constant-potential anodization has been applied to grow thick oxide films on 304 type stainless steel instead of traditional galvanostatic anodization. The thickness of the anodic films was tailored by tuning the applied anodization duration. The electrochemical performances of the anodic films with adjustable thickness are further evaluated for potential supercapacitor applications.

\section{EXPERIMENTAL}

In the experiments, the SUS 304-type SS foils containing C (0.07 wt\%), $\mathrm{Cr}(17.01 \mathrm{wt} \%), \mathrm{Ni}(8.02 \%)$ and $\mathrm{Fe}$ balance was used as the anodizing substrate. Prior to anodization, all samples were ultrasonically cleaned in acetone and distilled water respectively for 15 minutes followed by air drying. Then, the anodization of SS foils was carried out in ethylene glycol containing $0.1 \mathrm{M}$ distilled water and $0.1 \mathrm{M} \mathrm{NH} 4 \mathrm{~F}$ using a two-electrode cell. The SS foils worked as anode and graphite plate ( $2 \mathrm{~mm}$ in thickness) as cathode. Both were immersed in asmade electrolyte (10 $\mathrm{mm}$ in depth) parallel with each other. The distance between the two electrodes was fixed at $3.5 \mathrm{~cm}$. The potential of $50 \mathrm{~V}$ was employed for 1,2 and $3 \mathrm{~h}$, respectively. During the anodization process, the long-term anodization was kept by slightly decreasing electrolyte temperature to rescrict the temperature rise. The as-fabricated samples were soaked in $99.9 \%$ ethanol for $1 \mathrm{~h}$ followed by annealing at $500{ }^{\circ} \mathrm{C}$ in air for $3 \mathrm{~h}$.

The morphology of as-fabricated oxide layer was performed using Scanning Electron Microscope (SEM, Hitachi SU8230), with an acceleration voltage of $3 \mathrm{kV}$. The crystal phase and chemical composition were characterized by X-Ray diffraction (XRD) using X-Ray diffractometer (Equinox 1000) with Cu K-a radiation (Wavelength $\lambda=1.5 \AA$ ), acceleration voltage of $40 \mathrm{kV}$ from $10^{\circ}$ to $80^{\circ}$. The electrochemical characterization including cyclic voltammetry (CV), galvanostatic charging-discharging (GCD) and electrochemical impedance spectroscopy (EIS) were performed by Electrochemical workstation (CHI660E).

\section{RESULTS AND DISCUSSION}

The formation process of the anodic films can be studied by analyzing current transients during anodization of $\mathrm{SS}$ foils. As shown in Figure 1, the formation current is produced at a constant dc voltage of $50 \mathrm{~V}$ for 1,2 and $3 \mathrm{~h}$, respectively. Clearly, the formation current quickly increases to a peak value and then dramatically decreased to a minimum value at the early stage of anodizing process, indicating the barrier layer was quickly formed at $50 \mathrm{~V}$. Thereafter, the formation current slightly increases to a steady value, suggesting a competitive equilibrium was reached between anodizing and etching of SS foils. In the equilibrium state, the anodic film with self-organized nanopores will be developed on the surface of stainless steel foils. Correspondingly, the color of SS foils was changed from silvery white to deep yellow after anodization and then become dark black after subsequent annealing process. Furthermore, the current transients formed at $50 \mathrm{~V} / 1 \mathrm{~h}$ and $50 \mathrm{~V} / 2 \mathrm{~h}$ are overlapped with that formed at $50 \mathrm{~V} / 3 \mathrm{~h}$, indicating the long-term anodization could be achieved and repeated.

Figure 2 presents the SEM images of self-organized nanoporous anodic films formed on the surface of SS foils by constant potential anodization of $50 \mathrm{~V}$ for $1 \mathrm{~h}, 2 \mathrm{~h}$ and $3 \mathrm{~h}$, respectively annealed at $500{ }^{\circ} \mathrm{C}$ in air. As shown in Figure $\mathbf{2 a}$, the self-organized pores exhibited a quasi-honeycomb nanostructure with pore diameters ranging from 45 to $60 \mathrm{~nm}$. Correspondingly, the thickness of 8.9, 16.8, $26.9 \mu \mathrm{m}$ anodic layer was respectively formed as shown in Figures $\mathbf{2 b}$-d. It was further noted that the thickness of anodic film increases linearly with the anodization time, indicating the competitive equilibrium could be kept for a long duration. However, more cracks were observed across the thicker anodic films, which were possibly produced and further amplified by residual stress during film growing process and subsequent annealing process. 


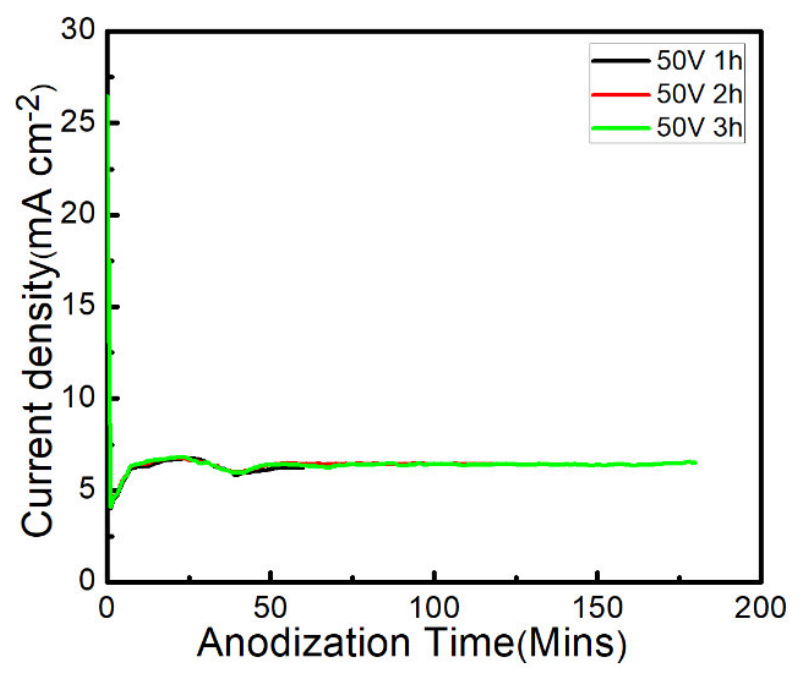

Figure 1 Current-time responses during anodization of 304 type stainless steel at $50 \mathrm{~V}$ for $1 \mathrm{~h}, 2 \mathrm{~h}, 3 \mathrm{~h}$
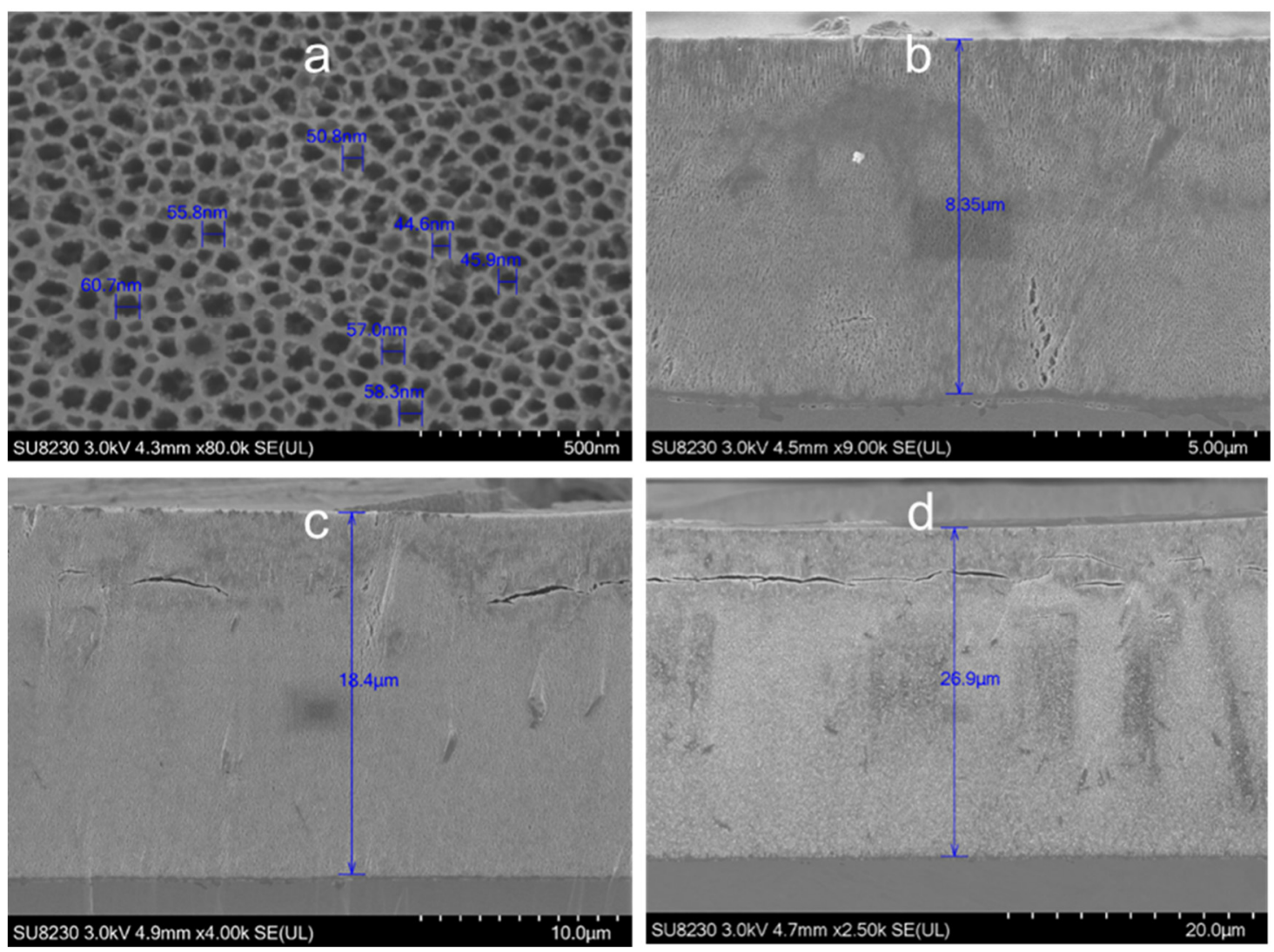

Figure 2 SEM images of porous anodic layer anodized at 50 for $1 \mathrm{~h}$ : (a) top surface; Cross sectional of (b) $50 \mathrm{~V} / 1 \mathrm{~h},(\mathrm{c}) 50 \mathrm{~V} / 2 \mathrm{~h},(\mathrm{~d}) 50 \mathrm{~V} / 3 \mathrm{~h}$

The XRD profiles of all anodic films are shown in Figure 3. There are no obvious sharp XRD peaks of the anodic film before annealing, suggesting the pristine anodic film is amorphous in nature. After the annealing process, the sharp XRD peaks were gradually appeared and suggest the annealed anodic films own crystalline structures. The sharp characteristic peaks further indicate that the annealed anodic films are predominantly composed of three phases of hematite $\left(\mathrm{Fe}_{2} \mathrm{O}_{3}\right)$, eskolaite $\left(\mathrm{Cr}_{2} \mathrm{O}_{3}\right)$ and spinel $\left(\mathrm{Fe}_{3} \mathrm{O}_{4}\right.$ and $\left.\mathrm{FeCr}_{2} \mathrm{O}_{4}\right)$ [14]. 


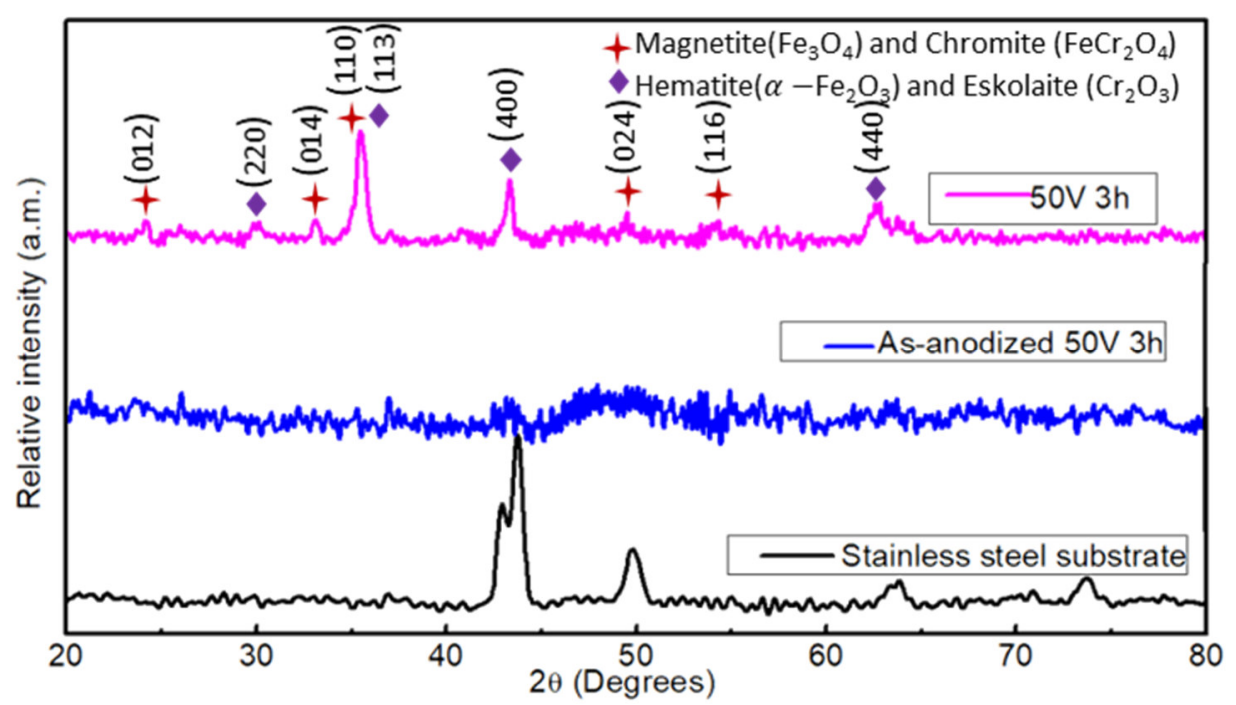

Figure $3 \mathrm{XRD}$ profile of the anodized stainless steel substrate at $50 \mathrm{~V}$ for $1 \mathrm{~h}$ before and after annealing

Figures $4 a-b$ show the $C-V$ curves of the anodic layers formed at $50 \mathrm{~V}$ for 1,2 and $3 \mathrm{~h}$ at the scan rate of $5 \mathrm{mV} \mathrm{s}^{-1}$, respectively. As shown in Figure 4a, all C-V curves exhibit a nearly symmetric shape when tested as a binder-free electrode, indicating good reversibility of faradaic redox reactions. Clearly, the anodic oxide film formed at $50 \mathrm{~V} / 3 \mathrm{~h}$ exhibits the largest integral area and thus indicates the highest specific capacitance among the three samples. The results indicate that increasing thickness of anodic film for more active materials could enhance the specific capacitance. As shown in Figure 4b, CV curves of the anodic layers formed at 50 $\mathrm{V} / 3 \mathrm{~h}$ at different scan rates varying from 5 to $100 \mathrm{mV} \mathrm{s}^{-1}$ were further studied. With increasing the scan rate, the shape of $C V$ curves remain unchanged, indicating that the material has good faraday reaction reversibility.

This phenomenon was further illustrated by GCD properties as shown in Figures 4c-d. As shown in Figure 4c, all curves display a deviation of regular triangle, confirming that the active materials have excellent electrochemical reversibility. The longest charge and discharge time take place in the anodic oxide film formed at $50 \mathrm{~V} / 3 \mathrm{~h}$, which exhibits the highest specific capacitance among all samples. The anodic layer exhibits the specific area capacitance $\sim 110.4,156.9$ and $215.2 \mathrm{mF} \mathrm{cm}^{-2}$ at the current density of $1 \mathrm{~mA} \mathrm{~cm}^{-2}$, respectively formed at $50 \mathrm{~V} / 1 \mathrm{~h}, 50 \mathrm{~V} / 2 \mathrm{~h}$ and $50 \mathrm{~V} / 3 \mathrm{~h}$. Obviously, the specific capacitance of anodic film is not proportional to their thickness, indicating the mass of active materials could not be fully utilized at thicker anodic film. The supercapacitance behavior of the anodic layers formed at $50 \mathrm{~V} / 3 \mathrm{~h}$ is further evaluated by performing GCD tests at various current densities ranging from 1 to $4 \mathrm{~mA} \mathrm{~cm}^{-2}$ as shown in Figure $4 \mathrm{~d}$. The discharge time decreases with increasing current density, indicating that the ion diffusion is limited at higher current density. Furthermore, the area-specific capacitance was respectively found to be $\sim 215.2 \mathrm{mF} \mathrm{cm}^{-2}$ at $1 \mathrm{~mA} \mathrm{~cm}^{-2}$ and $\sim 127.5 \mathrm{mF} \mathrm{cm}^{-2}$ at $4 \mathrm{~mA} \mathrm{~cm}-2$, and appropriately $59.2 \%$ capacitance is still retained at high current density, demonstrating good rate capability.

To compare the performance of resistance and capacitance for the anodic films with different thickness, electrochemical impedance spectroscopic (EIS) experiments were further conducted as shown in Figure 4e. In high frequency region, the anodic film formed at $50 \mathrm{~V} / 1 \mathrm{~h}$ shows the lowest equivalent series resistance (ESR, RS) among all sample, which are associated with ionic resistance of electrolytic solution, internal resistance of nanostructure and the contact resistance between the formed porous nanostructure and stainless steel substrate $[15,16]$. The possible reason is that the lower amount of active materials leads to lower RS due to thinner film. In the low frequency region, the anodic film formed at $50 \mathrm{~V} / 1 \mathrm{~h}$ exhibits more vertical line, revealing the lower diffusion resistance. The possible reason is that, it is more difficult for electrolyte ions to penetrate into thicker nanoporous anodic films. 

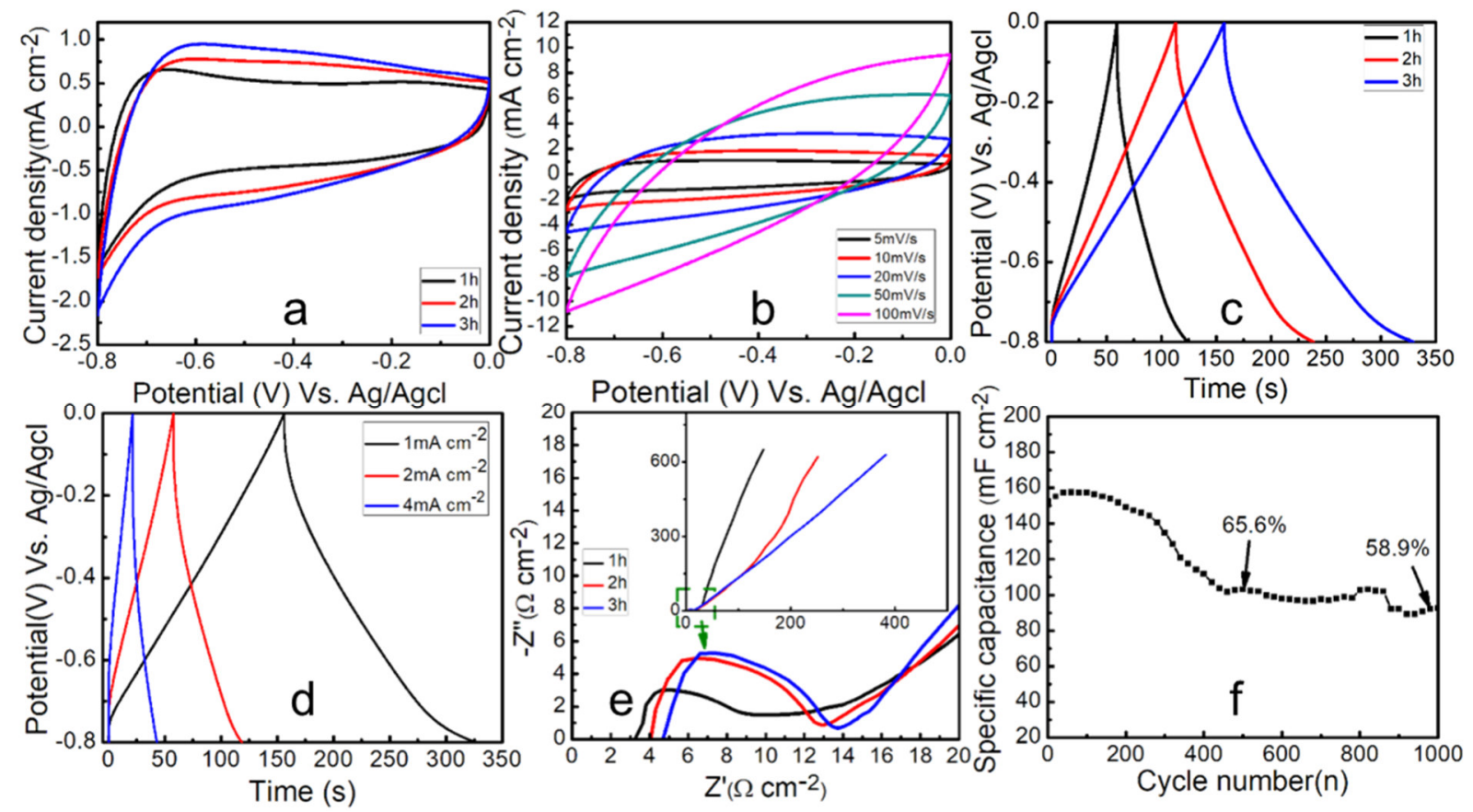

Figure 4 (a) CV curves of all anodic films at a scan rate of $5 \mathrm{mV} \mathrm{s}^{-1}$. (b) CV curves of the anodic films formed at $50 \mathrm{~V} / 3 \mathrm{~h}$ at the scan rates from 5 to $100 \mathrm{mV} \mathrm{s}^{-1}$. (c) GCD curves of all anodic films formed at at a current density of $1 \mathrm{~mA} \mathrm{~cm}^{-2}$. (d) GCD curves of the anodic film formed at $50 \mathrm{~V} / 3 \mathrm{~h}$ at current densities from 1 to 4 $\mathrm{mA} \mathrm{cm}^{-2}$. (e) Nyquist plots of all anodic films measured in the frequency range from 0.01 to $1 \mathrm{MHz}$. (f) Cycling stability of the anodic film formed at $50 \mathrm{~V} / 3 \mathrm{~h}$ at a current density of $2 \mathrm{~mA} \mathrm{~cm}-2$ for 1000 cycles.

Electrochemical stability of the anodic film formed at $50 \mathrm{~V} / 3 \mathrm{~h}$ was further investigated by repeating the GCD test at $2 \mathrm{~mA} \mathrm{~cm}^{-2}$ for 1000 cycles, as shown in Figure $\mathbf{4 f}$. It can be seen that the area capacitance slightly increases at first 100 cycles due to a possible activation process. Then, the specific capacitance decreases gradually during the following cycles, which is caused by the partially peeling-off active materials into electrolyte. Finally, the capacitance still retained $58.9 \%$ of its initial value after 1000 GCD cycles, indicating excellent electrochemical stability.

\section{CONCLUSIONS}

In summary, ultra-thick nanostructured anodic films have been fabricated on 304 stainless steel via long-term constant-potential anodization instead of galvanostatic anodization. It is found that the thickness of anodic film increases linearly with the anodization time while the specific capacitance of anodic film is not proportional to the thickness because it is more difficult for electrolyte ions to penetrate into thicker nanoporous anodic films. When tested as a binder-free electrode, the formed anodic layers formed at $50 \mathrm{~V} / 3 \mathrm{~h}$ exhibit the highest area capacitance $\sim 215.2 \mathrm{mF} \mathrm{cm}^{-2}$ at $1 \mathrm{~mA} \mathrm{~cm}^{-2}$, and the capacitance still retained $58.9 \%$ of its initial value after 1000 cycles.

\section{ACKNOWLEDGEMENTS}

This work was financially supported by Norwegian PHD Network on Nanotechnology for Microsystems and Micro Energy Team at University of South-eastern Norway. 


\section{REFERENCES}

[1] ZHAO, J.; LI, Y.; WANG, G.; WEI, T.; LIU, Z.; CHENG, K.; YE, K.; ZHU, K.; CAO, D.; FAN, Z., Enabling highvolumetric-energy-density supercapacitors: designing open, low-tortuosity heteroatom-doped porous carbon-tube bundle electrodes, Journal of Materials Chemistry A. 2017. vol. 5, iss. 44, pp. 23085-23093.

[2] LI, G., LI, J., LI, T., WANG, K., TiO2 nanotube arrays on silicon substrate for on-chip supercapacitors, Journal of Power Sources. 2019. vol. 425, pp, 39-43.

[3] WU, C.; CAI, J.; ZHU, Y.; ZHANG, K., Hybrid reduced graphene oxide nanosheet supported Mn-Ni-Co ternary oxides for aqueous asymmetric supercapacitors, ACS Applied Materials \& Interfaces. 2017. vol. 9, iss. 22, pp. 19114-19123.

[4] LI, G., CHANG, Z., LI, T., MA, L., WANG, K., Hierarchical Mn-Co sulfide nanosheets on nickel foam by electrochemical co-deposition for high-performance pseudocapacitors, lonics. 2019. iss. 177, pp. 1-11.

[5] CHENG, J.; LU, Y.; QIU, K.; YAN, H.; XU, J.; HAN, L.; LIU, X.; LUO, J.; KIM, J. K.; LUO, Y., Hierarchical Core/Shell NiCo2O4@NiCo2O4 nanocactus arrays with dual-functionalities for high performance supercapacitors and Li-ion batteries, Sci Rep. 2015. vol. 5, no. 12099 pp. 1-12.

[6] LIU, B.; WANG, Q.; WANG, X.; XIANG, Q.; CHEN, D.; SHEN, G., New energy storage option: toward ZnCo2O4 nanorods/nickel foam architectures for high-performance supercapacitors, ACS Appl Mater Interfaces. 2013. vol 5, iss. 20, 10011-10017.

[7] REDDY, A. E.; ANITHA, T.; MURALEE GOPI, C. V. V.; SRINIVASA RAO, S.; KIM, H. J., NiMoO4@NiWO4 honeycombs as a high performance electrode material for supercapacitor applications, Dalton Trans. 2018. iss. 27, 9057-9063.

[8] WANG, J.; ZHANG, L.; LIU, X.; ZHANG, X.; TIAN, Y.; LIU, X.; ZHAO, J.; LI, Y., Assembly of flexible CoMoO4@NiMoO4·xH2O and Fe2O3 electrodes for solid-state asymmetric supercapacitors, Sci Rep. 2017.vol. 7, no. 41088, pp. 1-11.

[9] KURE, K., KONNO, Y., TSUJI, E., SKELDON, P., THOMPSON, G.E., HABAZAKI, H., Formation of self-organized nanoporous anodic films on Type 304 stainless steel, Electrochemistry Communications. 2012. vol. 21, pp. 1-4.

[10] KLIMAS, V., PAKSTAS, V., VRUBLEVSKY, I., CHERNYAKOVA, K., JAGMINAS, A., Fabrication and characterization of anodic films onto the type-304 stainless steel in glycerol electrolyte, J Phys Chem C. 2013. vol. 117, pp. 20730-20737.

[11] LU, W., ZOU, D., HAN, Y., LIU, R., TIAN, C., Self-organised nanoporous anodic films on superaustenitic stainless steel, Materials Research Innovations. 2014. vol. 18, pp. 747-750.

[12] ZHANG, B.W., NI, H.W., CHEN, R.S., ZHAN, W.T., ZHANG, C., LEI, R., ZHA, Y.X., A two-step anodic method to fabricate self-organised nanopore arrays on stainless steel, Applied Surface Science. 2015. vol. 351, pp. 11611168.

[13] TAVEIRA, L.V., MACAK, J.M., SIROTNA, K., DICK, L.F.P., SCHMUKI, P., Voltage oscillations and morphology during the galvanostatic formation of self-organized TiO2 nanotubes, J. Electrochem. Soc. 2006. vol. 152, pp. B405-B410.

[14] SARMA, B., SMITH, Y., JUROVITZKI, A.L., RAY, R.S., MOHANTY, S.K., MISRA, M., Supercapacitance behavior of porous oxide layer grown on 302 type stainless steel substrate, J. Power Sources. 2013. vol. 236, pp. 103-111.

[15] XU, J., SUN, Y., LU, M., WANG, L., ZHANG, J., TAO, E., QIAN, J., LIU, X., Fabrication of the porous MnCo2O4 nanorod arrays on Ni foam as an advanced electrode for asymmetric supercapacitors, Acta Materialia. 2018. vol. 152, pp. 162-174.

[16] XU, J., SUN, Y., LU, M., WANG, L., ZHANG, J., LIU, X., One-step electrodeposition fabrication of Ni3S2 nanosheet arrays on $\mathrm{Ni}$ foam as an advanced electrode for asymmetric supercapacitors, Science China Materials. 2018. vol. 62. pp. 699-710. 